5. Несоблюдение скоростного режима. Конечно возможно оборудовать все транспортные средства контроллерами скорости привязав их координаты через ГЛОНАС, но это приведет к значительному подорожанию транспортных средств. В очередной раз становится понятно, что и здесь основная причина, желания водителя транспортного средства.

6. Неуверенность водителя транспортного средства. Участник дорожного движения недавно получивший водительское удостоверение, не имеет достаточного опыта управления транспортным средством. Конечно можно ввести некоторые законодательные ограничения, но и здесь прежде всего важна сознательность водителя транспортного средства, его желание осознанно соблюдать правила дорожного движения.

Здесь мы рассмотрели далеко не все причины дорожно-транспортных происшествий, но рассмотрев основные из них, мы приходим к выводу, что основная причина совершения ДТП несознательность водителя управляющего транспортным средством. В государственном управлении существует два универсальных метода урегулирования общественных отношений: убеждение и принуждение. Большинство участников дорожного движения соблюдают правила дорожного движения, боясь наступления ответственности. Выезжают на полосу для движения общественного транспорта и сворачивают с нее только возлекамеревидеофиксации, используют антирадары или специально программное обеспечение, чтобы избежать ответственности.

По нашему мнению это метод безусловно эффективен, но только до определенного момента. Задачей государства в целом и ГИБДД, как основного органа координирующего процессы в сфере безопасности дорожного движения, добиться от участников дорожного движения полного неприятия к правонарушениям за рулем. Это невозможно сделать без целенаправленной, планомерной профилактической работы и основная роль в профилактике ДТП ложится на плечи ГИБДД.

$$
* * *
$$

1. WHO Library Cataloguing-in-Publication Data: Global status report on road safety 2013: supporting a decade of action. WorldHealthOrganization. 2013. ISBN 97892 456456. C.

2. Доклад «Противостояние «Смерти на колесах. Обеспечение безопасности дорожного движения в Европе и Центральной Азии» : www.worldbank.org.

3. Кодекс Российской Федерации об административных правонарушениях: от 30.12.2001 № 195-Ф3

4. О безопасности дорожного движения: Федеральный закон от 10.12.1995 N 196-Ф3

\title{
Шматова Е.С., Золотарева Л.И. \\ Международное сотрудничество в сфере экологии: реализация Киотского протокола и перспективы Парижского соглашения
}

Южно-Российский государственный политехнический университет (НПИ) имени М.И Платова

doi:10.18411/spc-20-03-2018-13

(Россия, Новочеркасск)

idsp: 000001:spc-20-03-2018-13

\section{Аннотация}

Статья посвящена исследованию международного сотрудничества в сфере охраны окружающей среды по решению одной из основных экологических проблем современности - изменению климата на планете в связи с выбросом парниковых газов. Проведен анализ Киотского протокола как важнейшего международного документа по охране окружающей среды с констатацией целей и механизма его реализации. Рассмотрены аспекты участия ведущих стран мира в выполнении обязательств, предусмотренных в рамках Киотского протокола. Приведены точки зрения по наиболее 
актуальным вопросам действия Киотского протокола. Акцентируется внимание на основных результатах исполнения протокола и на его недостатках в сравнении с Парижским соглашением. Определены перспективы и основные аспекты Парижского соглашения, пришедшего на смену Киотскому протоколу. Делаются выводы о необходимости укрепления международного сотрудничества в области охраны окружающей среды и разработке дополнительных инструментов в решении проблем в сфере экологии.

Ключевые слова: международное экологическое право, охрана окружающей среды, глобальное потепление, международное сотрудничество в сфере экологии, Киотский протокол, Парижское соглашение.

\section{Abstract}

The article is devoted to the investigation of the international cooperation in environmental protection sphere on solving one of the main ecological problems of the present time - changing of climate at the planet due to greenhouse gas emissions. The analysis of Kyoto protocol as the most important international document on the environment safety is conducted with statement of its purposes and implementation mechanism. The aspects of participation of the leading countries in implementation of the liabilities within Kyoto protocol are considered. The opinions are given on the most actual issues of Kyoto protocol operation. The attention is focused on the main results of the protocol implementation and its disadvantages in comparison with Paris agreement. The prospects of Paris agreement replacing Kyoto protocol are defined. The conclusions on necessity of strengthening the international cooperation in the field of environmental protection and development of the additional instruments in solving the problems in ecological sphere are made.

Key words: international ecological right, environment protection, global warming, international collaboration in ecological sphere, Kyoto protocol, Paris agreement.

Экологические проблемы на нашей планете актуализировались сравнительно недавно - к концу XX - началу XXI веков. Их обострение связано с интенсивным увеличением численности человечества, с необходимостью использования большого количества природных ресурсов, с проблемой утилизации отходов, развитием автомобилестроения, перерабатывающей промышленности и т.д. В результате, указанные факторы явились причиной возникновения глобальных проблем в сфере экологии, решить которые возможно посредством реализации принципа международного сотрудничества государств. Подтверждением данного тезиса является мнение профессора К.А. Бекяшева, который отмечает, что "международные экологические проблемы должны решаться на общих принципах и правилах сотрудничества между суверенными государствами, подкрепляемых силой убеждения и переговорами" [13, с. 507]. Тем самым, решение экологических проблем на планете возможно лишь путем установления диалога между государствами при определении направлений сотрудничества в сфере охраны окружающей среды.

На наш взгляд, одной из наиболее серьезных экологических проблем современности является глобальное потепление климата в связи с масштабными выбросами в атмосферу парниковых газов. Парниковые газы разрушают защитный озоновый слой Земли и, тем самым, вызывают рост средней температуры на планете. Так, по данным Всемирной метеорологической организации, в 2016 году повышение средней температуры на планете было зафиксировано в диапазоне 1,2 градуса по Цельсию. При этом в арктической части воздух прогрелся на 6-7 градусов больше средней температуры [25], что привело к таянию ледников, отражающих солнечный свет. В целом, прослеживается тенденция ежегодного роста средней температуры на 
планете. Последствия изменения температуры воздуха и воды отражаются на флоре и фауне.

Данная проблема в сфере охраны окружающей среды наиболее актуальна, поскольку рост выбросов парниковых газов будет зависеть от экологической политики каждой страны и от общего участия мирового сообщества в решении проблем глобального потепления. Осознавая масштабность негативных последствий повышения среднегодовой температуры, в рамках Организации Объединенных Наций страныучастницы активно сотрудничают по вопросам сохранения климата на планете. В связи с этим, 9 мая 1992 года в г. Нью-Йорк была принята Рамочная конвенция ООН об изменении климата, которую подписали более 180 стран мира, а 21 марта 1994 года она вступила в силу [1]. Целью данной конвенции стала стабилизация концентраций парниковых газов в атмосфере на таком уровне, который не допускал бы опасного антропогенного воздействия на климатическую систему. Однако, поскольку Конвенция не содержала количественных обязательств, то для их определения разработан дополнительный документ - Киотский протокол. Киотский протокол был принят 11 декабря 1997 года в г. Киото (Япония) 159 странами и вступил в силу 16 февраля 2005 года [2]. Основной целью Киотского протокола стало сокращение выбросов парниковых газов в атмосферу по сравнению с базовым уровнем, в качестве которого был выбран уровень 1990 года. Согласно ст. 3 Киотского протокола, "начиная с 1990 года, стали происходить изменения в величине выбросов парниковых газов" [2], что отрицательно отразилось на состоянии окружающей среды. Следовательно, страны, подписавшие протокол, стремились сократить уровень выбросов парниковых газов, поэтому договорились о том, что в течение первого периода реализации Киотского протокола, который длился с 1 января 2008 года до 31 декабря 2012 года, общий объем выбросов в атмосферу двуокиси углерода, метана и других промышленных газов в соответствии со ст. 3 протокола должен быть сокращен на 5\% по сравнению с уровнем 1990 года [2].

Специфика Киотского протокола заключается в том, что он основан на рыночном механизме регулирования: государства или отдельные хозяйствующие субъекты на их территории могут продавать или покупать квоты на выбросы парниковых газов на национальном, региональном или международном рынках. Квота, в свою очередь, представляет собой норму выбросов парниковых газов, допустимых согласно Киотскому протоколу. Если какая-либо страна не использует эти квоты, то она может продать их стране, использовавшей свои квоты. Суть этого механизма заключается в том, что он позволяет сокращать выбросы парниковых газов в индустриально развитых странах за счет квот, покупаемых у других, в основном развивающихся, стран [8, с. 29]. Как отмечает в своем исследовании Е.В. Матвеева, "большинство стран мира, подписавших и ратифицировавших Киотский протокол, уже используют его механизмы" [12, с. 39]. Так, например, открыты биржи по торговле квотами на выбросы парниковых газов в Австралии, Великобритании и Дании. А эксперты ООН считают, что "такой механизм должен способствовать поступлению в развивающиеся страны значительных ресурсов, которые они могут использовать для борьбы с негативными тенденциями, вызванными изменением климата" [10]. Благодаря рассмотренному выше механизму квот, за время действия Киотского протокола реализовано 55 млн. тонн выбросов парниковых газов [12, с. 40]. Как видим, механизмы сокращения выбросов парниковых газов являются эффективным средством достижения целей Киотского протокола.

Основные обязательства по выполнению Киотского протокола взяли на себя США, страны ЕС, Япония, Канада, страны Восточной Европы и Прибалтики. Так, Евросоюз должен был сократить выбросы парниковых газов на 8\%, США - на 7\%, Япония и Канада - на 6\%, страны Восточной Европы и Прибалтики - на 8\%. Россия и 
Украина обязались сохранить среднегодовые выбросы в 2008-2012 годах на уровне 1990 года.

Однако, впоследствии стало известно, что Индия и Китай, на которых суммарно приходится $20 \%$ общемирового выбросов парниковых газов, не взяли на себя обязательств по Киотскому протоколу. А США, на долю которых приходится 24\% общемирового выброса парниковых газов, вовсе заявили о выходе из него еще весной 2001 года [8, с. 30], несмотря на тот факт, что США занимают второе место по выбросам парниковых газов в мире [6]. Причиной выхода стало то, что "осуществление Киотского протокола серьезно повредит американскую экономику". Кроме того, бывший Президент США Джордж Буш заявил, что США будет поддерживать сокращение выбросов посредством добровольного действия и новых энергетических технологий.

В декабре 2011 году вышла из Киотского соглашения и Канада. По словам премьер-министра Канады Харпера: "за несоблюдение нормативов о сокращении выбросов в требуемом объеме к 2012 году стране будет грозить штраф, эквивалентный 14 млрд. канадских долларов" [9]. А это экономически неэффективно. Кроме того, в случае с Канадой присутствует и политический подтекст, поскольку, по словам канадского министра экологии Питера Кента, "соглашение все равно не работает, поскольку действие Киотского протокола не распространяется на двух мировых лидеров по выбросам парниковых газов - США и Китай" [9]. Таким образом, основной причиной отказала некоторых стран от обязательств по Киотскому протоколу являются большие затраты, которые необходимо вложить в реализацию протокола, но не каждая страна готова позволить включить эти затраты в свой бюджет.

Россия, в свою очередь, подписала Киотский протокол в марте 1999 года, а ратифицировала в 2005 году. Причиной тому явился тот факт, что согласно ст. 25 Киотского протокола, он вступает в силу тогда, когда его ратифицируют страны, суммарные выбросы парниковых газов которых составляют 55\% от выбросов всех стран, участвующих в протоколе [10]. Если бы Россия, являясь источником около 17\% выбросов парниковых газов, не ратифицировала протокол, то необходимые 55\% набрать бы не удалось. Таким образом, от ратификации Россией Киотского протокола зависело его вступление в силу, поэтому было принято решение ратифицировать его.

Говоря об исполнении Киотского протокола, можно отметить, что страныучастницы EC, которые сокращают выбросы парниковых газов, призывают основных "загрязнителей" воздуха предпринять активные действия и ликвидировать негативное влияние выбросов на изменение климата. Кроме того, к 2020 году ЕС сформировал климатические и энергетические цели, а именно: сократить выбросы парниковых газов до 20\% от уровня 1990 года и увеличить до 20\% долю потребления энергии в ЕС от возобновляемых источников. ЕС также обещал сократить выбросы парниковых газов с 20 до 30\%, если ведущие экономические сообщества также предпримут меры по сокращению выбросов газов [23].

В октябре 2014 года лидеры стран ЕС разработали новые климатические и энергетические цели на 2030 год, включающие в себя сокращение выбросов парниковых газов до 40\% по сравнению с уровнем 1990 года; использование минимум $27 \%$ возобновляемых источников энергии; совершенствование мер по энергоэффективности до 27\%. К 2050 году ЕС стремится сократить выбросы практически на 95\% по сравнению с уровнем 1992 года [23]. Таким образом, мы видим, что ЕС активно реализует мероприятия, указанные в Киотском протоколе, посредством разработки собственных проектов и программ, направленных на сокращение выбросов парниковых газов. ЕС является одним из активных участников Киотского протокола, четко выполняющих все его условия.

Для России участие в Киотском протоколе необременительно, поскольку ей не пришлось сокращать выбросы и повышать энергоэффективность. России необходимо 
было к 2012 году сохранить объем выбросов на уровне 1990 года, и ей это удалось. Изза спада промышленного производства в 2000 году выбросы парниковых газов составили на 38\% ниже установленного лимита, а к 2010 году - на 34\% [16].

В связи с этим Россия стала продавать, а не покупать квоты, являясь вторым в мире поставщиком углеродных единиц после Китая. Так, в декабре 2010 года Россия начала продажу квот японским компаниям «Mitsubishi» и «Nippon Oil». Однако, председатель Правительства РФ Дмитрий Медведев отметил, что существенных коммерческих выгод от участия в протоколе Россия не получила. По словам главы Министерства иностранных дел Российской Федерации Сергея Лаврова, "Россия перевыполнила свои обязательства в рамках Киотского протокола и сегодня является лидером по общему снижению выбросов парниковых газов" [11]. Так, выбросы России составили на 31\% ниже показателей 1990 года, а выбросы от энергетического сектора в России за последние 20 лет снизились на 37\%. Кроме того, в рамках Киотского протокола Россия намерена была продолжать снижать выбросы парниковых газов, о чем заявил Д.А. Медведев в 2012 году на конференции ООН по устойчивому развитию в Рио-де-Жанейро, подтвердив, что к 2020 году Россия снизит выбросы парниковых газов на 25 \% к уровню 1990 года.

Говоря об итогах реализации первого периода обязательств по Киотскому протоколу, можно указать, что страны, взявшие на себя основные обязательства по коллективному снижению выбросов парниковых газов, сократили выбросы более чем на 20\% по сравнению с уровнем 1990 года [24]. Этот показатель превышает поставленную цель на 15\%. Таким образом, достижения по сокращению выбросов парниковых газов свидетельствуют о важности международного сотрудничества в сфере изменения климата, а Киотский протокол сыграл ключевую роль в решении глобальных проблем современности.

Однако, несмотря на положительные результаты протокола, необходимо отметить, что по истечении первого периода обязательств по Киотскому протоколу, который закончился в 2012 году, некоторые страны отказались участвовать во втором периоде, так называемом Киото-2, который начался в 2013 году. Об отказе участвовать в нем заявили такие страны, как Россия, Япония и Новая Зеландия. Основной причиной отказа участия некоторых стран в Киото-2 послужило то, что Киотский протокол не работал так, как изначально было задумано. Так, США и Китай, как самые крупные производители парниковых газов в мире, отказались участвовать в протоколе, не взяв на себя никаких обязательств. В свою очередь, страны, принявшие на себя обязательства по сокращению выбросов, ответственны только за $15 \%$ эмиссии парниковых газов [17].

По мнению О.Т. Цуциевой и А.Д. Татарбиевой, "очевидно, что принятых международным сообществом мер для предотвращения глобального потепления было недостаточно" [20, с. 224]. Ведь неэффективность Киотского протокола обуславливается тем, что он не был подписан ни США, ни Индией, ни Китаем. Например, около $40 \%$ снижения выбросов в результате действия Киотского протокола было компенсировано ростом эмиссий в странах, не взявших на себя обязательства. Доля парниковых эмиссий КНР, которая приходится на экспортное производство, выросла до 25\% в общем объеме выбросов Китая.

Стоит отметить, что, несмотря на отказ некоторых стран от участия во втором периоде обязательств по Киотскому протоколу, они продолжают снижать выбросы парниковых газов, но уже в рамках своей страны. Например, в России 30 сентября 2013 года вышел Указ Президента РФ "О сокращении выбросов парниковых газов" [4] и соответствующее Распоряжение Правительства РФ от 2 апреля 2014 года "Об утверждении плана мероприятий по обеспечению к 2020 году сокращения объема выбросов парниковых газов до уровня не более 75\% объема указанных выбросов в 1990 году" [5], в которое впоследствии Распоряжением Правительства РФ от 6 мая 2015 года 
были внесены изменения. Реализация данных документов, осуществляемая посредством выполнения предусмотренных в них мероприятий, проходит успешно, доказательством чего являются показатели сокращения выбросов парниковых газов: например, в конце 2015 года они снизились на 45,8\% по сравнению с 1990 годом; в 2016 - на 45,7\%; цифры за 2017 год пока не опубликованы, однако по предварительным данным Министерства экологии и природных ресурсов РФ тенденция продолжает улучшаться. Таким образом, несмотря на тот факт, что Россия отказалась участвовать во втором периоде обязательств по Киотскому протоколу, она активно продолжает выполнять мероприятия по снижению выбросов парниковых газов.

Итак, Киотский протокол сыграл немаловажную роль в решении глобальных климатических проблем в связи с выбросом парниковых газов, однако, у этого документа имеются и недостатки. А именно, что страны, на долю которых приходится основной объем выбросов парниковых газов, не заинтересованы в его выполнении. Кроме того, обязанности по Киотскому протоколу распределены между странамиучастницами неравномерно. Так, страны с переходной экономикой находятся в аналогичных условиях наряду с развитыми странами, которые в большей мере влияют на изменения климата. Например, развивающиеся страны тратят в 50-100 раз меньше средств на сокращение выброса одной тонны СО2, нежели индустриальные страны с высоким уровнем промышленного производства. Таким образом, несмотря на очевидные преимущества Киотского протокола, он имеет и множество противоречий. Тем не менее, обязательства по первому периоду Киотского протокола выполнены полностью, а по второму периоду, рассчитанному до 2020 года, продолжают выполняться.

После 2020 года, когда истечет срок действия второго периода обязательств по Киотскому протоколу, на смену ему придет новый документ, представляющий собой его продолжение, а именно - Парижское соглашение. Парижское соглашение было принято 196 сторонами Рамочной конвенции Организации Объединенных Наций об изменении климата (РКООНИК) на 21-й Конференции сторон РКООНИК, которая прошла в Париже 12 декабря 2015 года [19], а 4 ноября 2016 года Парижское соглашение вступило в силу спустя 30 дней после того, как его ратифицировали 55 стран, чьи суммарные выбросы СО2 составляют более 55\% от мирового объема. По состоянию на 1 июня 2017 года, его подписали 195 участников (ЕС и все государства, входящие в РКИК, за исключением Сирии и Никарагуа) и ратифицировали 148 стран. Россия подписала соглашение 22 апреля 2016 года, но пока не ратифицировала его. При этом, выдающийся русский ученый и юрист Ю.А. Тихомиров обращает внимание на тот факт, что в рамках Парижского соглашения "Россия приняла обязательства создать план адаптации к изменениям климата и ввести отчетность о его выполнении с 2020 года, а к 2030 году - уменьшить выбросы парниковых газов до 70\% от уровня 1990 года" [18, с. 6]. Целью Парижского соглашения, как и Киотского протокола, является значительное снижение выбросов парниковых газов, а также принятие мер, обеспечивающих ограничение роста общемировой температуры на планете на уровне 1,5-2 градуса по Цельсию. Осуществление Парижского соглашения имеет колоссальное значение для достижения целей в области устойчивого развития сотрудничества в сфере охраны окружающей среды. Парижское Соглашение представляет собой "дорожную карту" мер, которые позволят сократить выбросы и укрепить устойчивость к изменению климата, причем разработка и осуществление этих мер возлагается на национальные правительства. В качестве мер, предусмотренных Парижским соглашением, выступают: принятие национальных планов по снижению выбросов парниковых газов в атмосферу и их пересмотр в сторону усиления каждые пять лет; разработка к 2020 году национальной стратегии перехода на "зеленые" технологии и безуглеродную экономику; ежегодное выделение в Зеленый климатический фонд 100 млрд. долларов для помощи слаборазвитым и наиболее уязвимым странам [22]. После 
2025 года эта сумма должна быть пересмотрена в сторону увеличения с учетом потребностей и приоритетов развивающихся стран.

Так, например, в целях выполнения указанных национальных планов и стратегий, в России по Указу Президента РФ 2017 год был объявлен Годом экологии для привлечения внимания общества к вопросам экологического развития России, сохранения биологического разнообразия и обеспечения экологической безопасности [3]. В конце 2017 года были подведены предварительные итоги Года экологии, результатом которого стали выяснение основных причин катастрофического состояния многих природных объектов; разработка проектов по оздоровлению природных объектов; минимизация вредных выбросов и негативного воздействия на окружающую среду, а также внесение с 1 января 2018 года поправок в различные правовые акты, которые ужесточают ответственность, усиливают контроль и внедряют новый подход к оценке негативного влияния хозяйственной деятельности на окружающую среду [7].

Важно отметить, что Парижское соглашение, в отличие от Киотского протокола, не предусматривает механизма квот. В Парижском соглашении отсутствуют санкции для стран, не справляющихся с выполнением национальных вкладов. Соглашением всего лишь утверждается создание стимулирующего механизма, который должен поощрять государства и хозяйствующие субъекты за успешное сокращение ими выбросов парниковых газов [14]. Следовательно, страны, подписавшие Парижское соглашение, самостоятельно определяют количественные обязательства по снижению либо ограничению выбросов парниковых газов в соответствии со своей национальной стратегией. А поскольку выполнение этих обязательств зависит, прежде всего, от экономических и финансовых возможностей той или иной страны, то они могут выполняться, а могут и не выполняться.

Соглашение направлено на разработку новой низкоуглеродной модели экономического развития на основе постепенного отказа от традиционных технологий добычи, переработки и использования ископаемых ресурсов (прежде всего, углеводородного сырья) в пользу "зеленых" технологий. Для реализации программ сдерживания глобального потепления развивающимся странам будет предоставлена финансовая поддержка. Совокупное государственное и частное финансирование развивающихся стран к 2020 году должно достичь 100 миллиардов долларов.

В настоящее время Парижское соглашение ратифицировали 170 стран. Россия его пока не ратифицировала в связи с необходимостью принятия национальных документов по переходу на энергосберегающие технологии и введения соответствующих поправок в действующее законодательство. А США и вовсе 5 августа 2017 года официально заявили о выходе из Парижского соглашения. По словам Дональда Трампа, "США могли потерять 2,7 млн. рабочих мест к 2025 году, если бы выполняли положения соглашения". Кроме того, американский лидер полагает, что Парижское соглашение "перераспределяет американские богатства" в пользу других стран [22].

Как видим, достижение целевых показателей Парижского соглашения потребует значительного притока инвестиций в экологически чистые технологии. Так, по подсчетам BankofAmericaMerrillLynch, для достижения целевых показателей по росту температуры, необходимо увеличить к 2030 году приток инвестиций с 270 млрд. до 900 млрд. долларов в год [15]. Таким образом, ратификация Парижского соглашения, как и Киотского протокола, требует значительных финансово-экономических затрат от каждой страны-участницы соглашения, в том числе и для России.

Однако, в отличие от Киотского протокола, при реализации положений которого развитые экономики брали на себя четкие юридические обязательства по сокращению выбросов вредных веществ, Парижское соглашение, напротив, юридически обязательных требований по сокращению выбросов парниковых газов не предусматривает. Тем самым, если по каким-то причинам страна решит вернуться 
к своей стандартной политике в области климата, ей ничто не сможет помешать это сделать. Следовательно, при выполнении мер, указанных в Парижском соглашении, остается надеяться только на ответственность стран-участниц перед миром и будущими поколениями [21].

Таким образом, на основании вышеизложенного можно сделать следующий вывод: Киотский протокол является важным инструментом, направленным на сокращение выбросов парниковых газов и, тем самым, препятствует повышению общемировой температуры на планете. Киотский протокол основан на рыночном механизме регулирования, а именно, он предоставляет странам-участникам продавать или покупать квоты на выбросы парниковых газов на национальном, региональном или международном рынках. Киотский протокол предусматривает проекты по сокращению выбросов, а также разработку совместных проектов на территории одной из стран, полностью или частично за счет инвестиций индустриально развитых стран. И, несмотря на некоторые очевидные недостатки Киотского протокола, участвующим странам посредством его реализации удалось перевыполнить свои обязательства по сокращению выбросов парниковых газов на $15 \%$, что свидетельствует об эффективности Киотского протокола. А одной из наиболее серьезных проблем, снижающих его эффективность, выступает низкая заинтересованность в выполнении Киотского протокола основными странами-загрязнителями атмосферы. На смену этому протоколу пришло Парижское соглашение, цели и задачи которого аналогичны целям и задачам предыдущего документа. Однако, поскольку начало его реализации назначено на 2020 год, то возможность оценить его эффективность появится только после указанного периода. Следовательно, необходимо признать, что конвенционного механизма недостаточно в решении экологических проблем на планете. Поэтому государствам мира рекомендуется усилить международное сотрудничество в области охраны окружающей среды и сконцентрироваться на решении проблемы глобального потепления, разработать и внедрить дополнительные инструменты, например, создать международную межправительственную организацию в сфере экологии.

$$
* * *
$$

1. Рамочная конвенция Организации Объединенных Наций об изменении климата (заключена в г. Нью-Йорке 9 мая 1992 года) // Собрание законодательства РФ. 1996. № 46. Ст. 5204.

2. Киотский протокол к Рамочной конвенции Организации Объединенных Наций об изменении климата (Подписан в г. Киото 11 декабря 1997 года) // Бюллетень международных договоров. 2005. № 5. C. 3-23.

3. Указ Президента РФ от 5 января 2016 год № 7 (в ред. от 3 сентября 2016 года) "О проведении в Российской Федерации Года экологии" // Собрание законодательства РФ. 2016. № 2 (ч. I). Ст. 321.

4. Указ Президента РФ от 30 сентября 2013 года № 752 "О сокращении выбросов парниковых газов" // Собрание законодательства РФ. 2013. № 40. Ч. ІІІ. Ст. 5053.

5. Распоряжение Правительства РФ от 2 апреля 2014 года № 504-р (в ред. Распоряжения Правительства РФ от 17 июня 2016 года № 1247-р) "Об утверждении плана мероприятий по обеспечению к 2020 году сокращения объема выбросов парниковых газов до уровня не более 75 процентов объема указанных выбросов в 1990 году" // Собрание законодательства РФ. 2014. № 15. Ст. 1778 .

6. "Забота" о климате по-американски. США и Киотский протокол // Электронный ресурс. Режим доступа: https://www.vsetut.ru/zabota-o-klimate-po-amerikanski-ssha-i-kiotskiy-protokol [дата обращения 29.01.2018].

7. Завершение Года экологии в России [Текст] // Официальный сайт ЭкоЭксперт // Электронный pecypc. Режим доступа: https://xn--80anccgcwd3a3hra8a.xn--p1ai/news/zavershenie-goda-ekologii-vrossii [дата обращения 05.01.2018].

8. Какителашвили М.M. Перспективы участия России в Киотском протоколе // Экологическое право. 2016. № 2. C. 28-32.

9. Канада выходит из Киотского протокола // Российская газета // Электронный ресурс. Режим доступа: https://rg.ru/2011/12/13/kanada-site.html [дата обращения 29.01.2018].

10. Киотский протокол // Официальный сайт информационного агентства РИА Новости // Электронный peсурс. Режим доступа: https://ria.ru/spravka/20150216/1047544621.html [дата обращения 29.01.2018]. 
11. Лавров: Россия лидирует в мире по снижению выбросов парниковых газов // Официальный сайт информационного агентства РИА Новости // Электронный ресурс. Режим доступа: https://ria.ru/earth/20150927/1285988505.html [дата обращения 29.01.2018].

12. Матвеева Е.В. Проблема глобального изменения климата и Российская Федерация: итоги реализации Киотского протокола // Политические институты и процессы. 2015. № 2. С. 38-43.

13. Международное публичное право. Учебник [Текст] / Отв. ред. К.А. Бекяшев. 5-е изд., перераб. и доп. М.: Проспект, 2009. 1008 с.

14. Парижское соглашение по климату // Официальный сайт информационного агентства РИА Новости // Электронный peсурс. Режим доступа: https://ria.ru/spravka/20171212/1510681570.html [дата обращения 29.01.2018].

15. Полтора градуса: пять вопросов о Парижском соглашении по климату // Официальный сайт РБК // Электронный ресурс. Режим доступа: https://www.rbc.ru/economics/04/11/2016/581b09c09a7947d20350fa61 [дата обращения 29.01.2018].

16. Россия выходит из Киотского протокола // Ведомости // Электронный ресурс. Режим доступа: https://www.vedomosti.ru/politics/articles/2012/12/10/klimaticheskaya_izolyaciya [дата обращения 29.01.2018].

17. Россия вышла из Киотского протокола // Официальный сайт Ино ТВ // Электронный ресурс. Режим доступа: https://russian.rt.com/inotv/2012-12-11/Rossiya-vishla-iz-Kiotskogo-protokola [дата обращения 29.01.2018].

18. Тихомиров Ю.А. Сохранение климата - актуальная задача права // Право и экономика. 2016. № 6. C. 4-8.

19. Церемония подписания Парижского соглашения по климату // Официальный сайт Организации Объединенных Наций // Электронный ресурс. Режим доступа: http://www.un.org/sustainabledevelopment/ru/about/climate-change/ [дата обращения 29.01.2018].

20. Цуциева О.Т., Татарбиева А.Д. Проблемы реализации Киотского протокола // Актуальные проблемы гуманитарных и естественных наук. 2014. № 10. С. 222-225.

21. Что нужно знать о Парижском климатическом соглашении // Электронный ресурс. Режим доступа: http://onznews.wdcb.ru/news16/info_160307.html [дата обращения 29.01.2018].

22. Что нужно знать о Парижском соглашении по климату // Информационное агентство России ТАСС // Электронный pесурс. Режим доступа: http://tass.ru/obschestvo/3637582 [дата обращения 29.01.2018].

23. An official website of the European Union // Электронныйресурс. Режим доступа: https://europa.eu/european-union/topics/climate-action_en [дата обращения 05.01.2018].

24. International center of Trade and sustainable Development // Электронныйресурс. Режим доступа: https://www.ictsd.org/bridges-news/ [дата обращения 29.01.2018].

25. Provisional WMO Statement on the Status of the Global Climate in 2016 [Текст] // Электронныйресурс. Режим доступа: https://public.wmo.int/en/media/press-release/provisional-wmo-statement-status-ofglobal-climate-2016 [дата обращения 29.01.2018]. 